\title{
Código de ética del Nutricionista Clínico de la FELANPE
}

\author{
FELANPE's Code of Ethics for the Clinical Nutritionists \\ Código de ética do nutricionista clínico do FELANPE
}

\begin{abstract}
Lina María Sierra Tobón', Mónica López Talavera², Angélica Pérez Cano³, Claudia Maza Moscoso ${ }^{4}$, Agustina Senese ${ }^{5}$, Denise Van Aanholt ${ }^{6}$, Janett Karla Rodríguez ${ }^{7}, C^{2}$ ilia Sepúlveda ${ }^{8}$, Yadira Cortes ${ }^{9}$, Paula Sánchez ${ }^{10}$, Martha Beatriz Pérez Santana ${ }^{11}$, María Belén Andrade ${ }^{12}$, Sofía Rivas ${ }^{13}$, María José Sendrós ${ }^{14}$, Edna Nava ${ }^{15}$, Laura Joy ${ }^{16}$, Gladys Panduro ${ }^{17}$, Biannerys Céspedes ${ }^{18}$, Gertrudis Baptista ${ }^{19}$, Alejandra Texeira ${ }^{20}$.
\end{abstract}

Recibido: 1 de julio de 2021. Aceptado para publicación: 15 de julio de 2021.

https://doi.org/10.35454/rncm.v4supl1.350

\section{PREÁMBULO}

El ejercicio profesional del nutricionista clínico (también conocido como nutricionista o dietista) está en constante evolución, lo que conlleva a retos, dificultades y dilemas éticos. Esta evolución se explica principalmente por una sociedad diversa y pluralista, que interactúa de diferentes formas. La inclusión de nuevas tecnologías y los avances científicos propician el acceso a la información y la disponibilidad de evidencia científica gracias a la interacción en redes sociales.

Surge, entonces, la necesidad de un código de ética deontológico, entendido como una guía general para el ejercicio de la profesión, que reconoce que la actuación del profesional debe desarrollarse en libertad, para

\footnotetext{
Asesora. Correo electrónico: linamarst@hotmail.com

Asesora. Correo electrónico: mlt88rm@gmail.com

Asesora.Correo electrónico: angelica_perezc@hotmail.com

Asesora. Correo electrónico: cmaza34@hotmail.com

Argentina. Correo electrónico: agusenese@gmail.com

Brasil. Correo electrónico: deaanholt@gmail.com

Bolivia. Correo electrónico: karlitajanett79@hotmail.com

Chile. Correo electrónico: cecilia.sepulveda@umayor.cl

9 Colombia. Correo electrónico: nd.yadiracortes@gmail.com

10 Costa Rica. Correo electrónico: dra.paola.sanchez@gmail.com

11 Cuba. Correo electrónico: marthabeatrizperezsantana@gmail.com

12 Ecuador. Correo electrónico: mabeandrade28@gmail.com
}

facilitar el avance y la innovación, lo que asegura un serio compromiso y responsabilidad con la persona y la sociedad, compromiso al que se espera dar cumplimiento a través del código propuesto.

De este modo, el comité de nutricionistas de la FELANPE establece una serie de principios y normas, las cuales guían la conducta del nutricionista que se desempeña en el área clínica, en particular, en el campo asistencial (consulta y hospitalización), docente o de investigación. No se trata de una serie de normas exhaustivas que abarquen todas las posibles situaciones; por el contrario, son principios y normas generales que se deben tener en cuenta en el día a día.

Este código no pretende reemplazar las normas que regulan el ejercicio profesional de cada país, las cuales

\footnotetext{
13 El Salvador. Correo electrónico: sofiarivas22@gmail.com

14 España. Correo electrónico: msendrosm@gmail.com

15 México. Correo electrónico: ednajnava@hotmail.com

16 Paraguay. Correo electrónico: nutrición_joy@hotmail.com

17 Perú. Correo electrónico: gladyspanduro69@hotmail.com

18 República Dominicana. Correo electrónico: bcc.cespedes@gmail.com

19 Venezuela. Correo electrónico: tully_b@hotmail.com

20 Coordinadora. Correo electrónico: alejandratexeira@gmail.com
}

*Correspondencia: Lina María Sierra Tobón. integralclinicalnutrition@gmail.com 
se deben respetar según la legislación vigente. Se trata de una guía que hace énfasis en los deberes, derechos y límites de la práctica profesional, e indica que la actuación del nutricionista clínico se debe guiar por la ética y la defensa del derecho humano al cuidado nutricional.

El código ha tenido en cuenta que los profesionales deben ejercer con libertad y avanzar en el desarrollo e innovación de la práctica de la nutrición clínica, y el ejercicio de la profesión siempre debe centrarse en las necesidades y expectativas de pacientes, cuidadores, integrantes de la sociedad y los sujetos de investigación, con fundamento en la evidencia científica y el respeto por la dignidad humana.

El código se ha construido con base en los principios de la bioética médica (autonomía, no maleficencia, beneficencia y justicia), teniendo en cuenta la Declaración Internacional sobre Bioética y Derechos Humanos de la UNESCO y los principios establecidos en la Declaración Internacional de Cartagena sobre el derecho al cuidado nutricional y la lucha contra la malnutrición, lo que permite puntualizar el contrato ético y social, que dicta la responsabilidad profesional frente a las personas vulnerables, desde el punto de vista nutricional, de la sociedad y de la profesión.

Así las cosas, el código pone sobre el papel los principios y las normas sobre los cuales se fundamenta el ejercicio de los profesionales de la nutrición clínica; es decir, establece un terreno común a los nutricionistas en el campo clínico para su ejercicio científico humanizado, a partir de 5 principios deontológicos.

\section{RESPETO POR LA DIGNIDAD HUMANA}

El respeto por la dignidad humana es el pilar fundamental de la práctica de la nutrición clínica, lo que permite reconocer el valor intrínseco del ser humano y no vulnerar su integridad durante el proceso del cuidado nutricional. En el contexto profesional, considerando el principio de respeto por la dignidad humana, el nutricionista clínico basará su práctica en las siguientes normas:

- Actuar de manera tal que siempre se respete el valor intrínseco de cada ser humano. Para ello se debe tener en cuenta y respetar la individualidad y el contexto social, cultural, religioso, hábitos, preferencias y rechazos de toda persona que necesite dietoterapia o terapia médica nutricional.

- Favorecer el acceso de cada paciente a un cuidado nutricional continuo, el cual consta de tres etapas: detectar (tamizaje, valoración y diagnóstico), nutrir (terapia médica nutricional) y vigilar, respetando siempre la integridad de la persona.

- Actuar de manera considerada y respetuosa de la diversidad étnica, los valores culturales, las creencias y las opiniones de los pacientes y los sujetos de investigación.

- El nutricionista clínico es responsable del cuidado nutricional del paciente, de procurar su bienestar integral y el resguardo de su dignidad.

- El interés económico nunca debe ser la motivación principal en la toma de decisiones del nutricionista clínico.

\section{PROTECCIÓN A LA PERSONA EN CONDICIÓN DE VULNERABILIDAD NUTRICIONAL}

La persona enferma en estado de malnutrición está particularmente vulnerable desde el punto de vista social, físico y psicológico. La vulnerabilidad implica fragilidad y el cuidado nutricional adecuado y oportuno contribuye a la protección del vulnerable. En el contexto profesional, considerando el principio de respeto a la persona vulnerable en riesgo o en estado de malnutrición, el nutricionista clínico basará su práctica en las siguientes normas:

- Reconocer que, aunque todos somos vulnerables por la misma condición humana, existen personas con mayor manifestación de vulnerabilidad, dada por la presencia o riesgo de malnutrición, su condición de salud, sociocultural y de acceso a recursos, entre otras.

- La actuación del profesional de la nutrición clínica se debe guiar por la defensa del derecho humano a la salud, a la alimentación y al cuidado nutricional.

- La colaboración con quien sea pertinente es fundamental para hacer respetar los derechos humanos y promover la justicia y la objetividad en la distribución equitativa de las intervenciones nutricionales.

- Es responsabilidad del nutricionista clínico realizar el proceso de cuidado nutricional óptimo y oportuno.

- La participación en actividades que beneficien a la comunidad y logren la confianza de la población en la profesión es un aspecto relevante en la práctica profesional.

- El profesional de la nutrición clínica promoverá la conformación y participación en equipos interdisciplinarios de nutrición clínica que, con respeto mutuo, aseguren el cuidado nutricional de todas las personas en riesgo o en estado de malnutrición. 


\section{RESPETO POR LA AUTONOMÍA DEL PACIENTE EN EL EJERCICIO DE LA NUTRICIÓN CLÍNICA}

Las decisiones del nutricionista clínico se fundamentan en la responsabilidad frente al cuidado nutricional y en el respeto activo a la libertad de elección informada del paciente, así como en procurar que se den las condiciones necesarias y evitar cualquier obstáculo. El profesional tiene la responsabilidad de responder ante los problemas nutricionales de las personas sanas y enfermas cuando se requiera, siempre con el cuidado nutricional debido y considerando la vulnerabilidad de la persona enferma, sin realizar acciones fútiles que causen daño. En el contexto profesional, considerando el respeto por la autonomía, el nutricionista clínico basará su práctica en las siguientes normas:

- Respetar la autonomía del paciente o del sujeto de investigación. Esto implica el respeto de sus decisiones y en ningún caso actuar o realizar intervenciones en contra de su voluntad y del principio de no maleficencia, con el único objetivo de satisfacer su autonomía.

- Comunicar de manera acertada la información científica por cualquier medio (escrito, oral, electrónico), siempre teniendo en cuenta la información basada en la evidencia, con el único objetivo de beneficiar el estado nutricional y la salud física y mental del paciente, nunca el interés comercial.

- En caso de que la persona no sea competente en la toma de decisiones, se deberá facilitar el acceso a los mecanismos legales vigentes de cada país (familiar cercano, voluntades anticipadas, entre otros).

- Reconocer que el consentimiento informado se basa en el respeto a la dignidad del paciente y a su libre autonomía. Este es un proceso de comunicación continua entre el nutricionista y el paciente, un elemento de seguridad clínica, y se debe concebir como garantía para que el paciente intervenga en la toma de decisiones sobre su salud.

- Promover el empoderamiento del paciente y las familias sobre la nutrición y las alteraciones del estado nutricional, ofreciendo información certera basada en la evidencia y adaptada a la capacidad de entendimiento del paciente y cuidador, para favorecer decisiones autónomas e informadas sobre el cuidado nutricional y cumplir con el tratamiento nutricional sugerido.

- Facilitar la participación del paciente en la toma de decisiones. Esto se logra al asegurar el proceso con- tinuo de comunicación con el paciente, quien podrá recibir toda la información relativa a su salud, y en particular al estado nutricional y a los tratamientos (las posibles complicaciones de la terapia nutricional, los riesgos, los beneficios, las alternativas, entre otros) para que pueda tomar sus propias decisiones.

- Garantizar la confidencialidad de los pacientes o los sujetos de investigación. No revelar datos clínicos, ni imágenes audiovisuales en ningún medio (escrito, oral, electrónico) sin previa autorización.

\section{ADECUACIÓN TERAPÉUTICA EN LA TOMA DE DECISIONES}

El nutricionista clínico tiene la obligación de actuar en beneficio de la persona vulnerable y de no causar daño, ayudándole a promover sus legítimos intereses, mejorando su salud y calidad de vida. Para ello se tendrá en cuenta el principio de adecuación terapéutica, el cual lo orientará respecto a cuándo omitir o retirar la terapia médica nutricional. En el contexto profesional, considerando el principio de adecuación terapéutica, el nutricionista clínico basará su práctica en las siguientes normas:

- Fundamentar la práctica profesional según el enfoque de la nutrición basada en la evidencia, teniendo en cuenta los valores y las circunstancias particulares de los pacientes. Esto implica la toma de decisiones apoyada en la experiencia, el criterio clínico y el juicio profesional.

- Promover en las instituciones de salud un óptimo cuidado nutricional, el cual se debe considerar como un proceso continuo.

- Considerar que la terapia médica nutricional, es decir, la suplementación oral, la nutrición enteral y la parenteral, es un acto terapéutico, que necesita de una indicación clínica y del consentimiento del paciente.

- Considerar la dietoterapia, es decir, la modificación nutricional (con alimentos ordinarios), como una terapia individualizada (ajuste de la dieta como parte del cuidado básico), que requiere de la decisión y voluntad del paciente para seguir las indicaciones del nutricionista clínico.

- Recurrir a la abstención del acto terapéutico cuando la persona así lo requiera, o cuando la decisión se encuentre en contra de los principios éticos de beneficencia y no maleficencia.

- Estar consciente de las posibles complicaciones de la terapia nutricional que se contemple prescribir, guardando la adecuada proporción entre los medios empleados y el fin perseguido. 
- Participar desde un enfoque inter- y multidisciplinario en las decisiones que conciernen a los pacientes.

- Realizar una práctica en los límites de las competencias individuales del profesional al promover la colaboración con otros nutricionistas o profesionales, para buscar consejo y remitir cuando sea necesario, evitando caer en actos de negligencia.

- Consultar instancias superiores, como los comités de ética hospitalaria, cuando sea necesario.

- Proporcionar servicios de calidad y costo-efectivos que busquen la salud y el bienestar de los pacientes, procurando resguardar el uso de recursos públicos y privados.

\section{INVESTIGACIÓN Y DESARROLLO PROFESIONAL}

La competencia y el desarrollo profesional continuo es un deber ético; por tanto, promover la generación de conocimientos que permitan realizar un cuidado nutricional con fundamento científico es responsabilidad del nutricionista clínico. En el contexto profesional, considerando la investigación y el desarrollo profesional como deber ético, el nutricionista clínico basará su práctica en las siguientes normas:

- Preocuparse por el desarrollo continuo de sus competencias y mejorar la experticia en el campo de la nutrición clínica, reconociendo sus límites y adquiriendo conocimientos humanísticos para tomar decisiones en torno al debido cuidado que merece el paciente.
- Promover, desarrollar y participar en investigaciones, respetando los principios éticos para mejorar la práctica, la innovación y el avance de la ciencia de la nutrición.

- Promover la transparencia en la divulgación de la ciencia de la nutrición clínica y declarar cualquier tipo de conflicto de interés económico o de otra índole.

- Identificar, declarar y evitar conflictos de intereses de cualquier tipo, esto incluye el interés financiero por productos o servicios que se estén recomendando. Abstenerse de recibir regalos, viajes o servicios, que potencialmente influyan o que puedan, en apariencia, influir en el juicio profesional.

- Reconocer sus derechos y deberes, manteniéndose actualizado sobre la legislación relevante para el ejercicio profesional, los reglamentos y cargos de los consejos relacionados con su profesión y otras entidades de la categoría, así como otros organismos reguladores en el campo de la alimentación y la nutrición; por tanto, debe actuar según las leyes y códigos que regulen la práctica de la profesión, lo que implica obtener las credenciales y afiliaciones necesarias según las normas vigentes de cada país.

- Respetar la propiedad intelectual, no realizar plagio, citar correctamente las referencias bibliográficas y reconocer las ideas e iniciativas de otros profesionales en cualquier medio (escrito, oral, electrónico).

- Abstenerse de hacer declaraciones falsas, fraudulentas, engañosas o injustas.

- Demostrar respeto y profesionalismo en todas las comunicaciones, esto incluye las redes sociales. 